\title{
Assessing the Work Activities Related to Musculoskeletal Disorder among Critical Care Nurses
}

\author{
Aesha Abdullah Aleid $(D$, Hend Abdelmonem Eid Elshnawie $(\mathbb{D}$, and Ahmed Ammar (iD \\ Imam Abdulrhman Bin Faisal University, Dammam, Saudi Arabia \\ Correspondence should be addressed to Hend Abdelmonem Eid Elshnawie; haalshnawie@iau.edu.sa and Ahmed Ammar; \\ asammar@iau.edu.sa
}

Received 28 September 2020; Revised 21 April 2021; Accepted 20 May 2021; Published 30 June 2021

Academic Editor: Timothy Plackett

Copyright (C) 2021 Aesha Abdullah Aleid et al. This is an open access article distributed under the Creative Commons Attribution License, which permits unrestricted use, distribution, and reproduction in any medium, provided the original work is properly cited.

\begin{abstract}
Nurses are physically exhausted with an incidence of work-related musculoskeletal disorders (MSDs), especially those working in critical care units that require exhaustive physical efforts to fulfill patients' needs. The current study aims to assess work activities related to the occurrence of MSDs in nurses working in critical care units. A descriptive cross-sectional study was conducted on a sample of 100 nurses of critical care units, and the data were collected via a survey questionnaire. The study was conducted at King Fahad University Hospital for three months from February to April 2019. The study findings revealed that work activities related to MSD were associated with sociodemographic data, age, and neck pain (rho $=0.063)(p=0.03)$ and lower back pain (rho $=0.89)$ $(p=0.03)$; education level with hip/thigh pain $(\mathrm{rho}=0.64)(p=0.03)$; standing time with shoulder pain $(\mathrm{rho}=0.66)(p=0.04)$, wrist/hand pain $(\mathrm{rho}=-0.75)(p=0.05)$, hip/thigh pain $(\mathrm{rho}=-0.78)(p=0.004)$, and knee pain $(\mathrm{rho}=-0.77)(p=0.005)$. An increased prevalence of MSDs with lower back pain (92\%) and upper back pain (56\%) was estimated among the nurses, and a negative impact of work-related MSDs on occupational health and daily life activities of the nurses was also observed. The study concluded that the occurrence of MSDs is significantly associated with sociodemographic data: age, BMI experience level, and educational level of nurses of critical care units.
\end{abstract}

\section{Introduction}

Musculoskeletal disorder (MSD) is a condition associated with damage to the body tissues caused by continuous physical strain and trauma. This trauma causes pain and discomfort because of various inflammatory symptoms that affect muscles, tendons, ligaments, joints, blood vessels, and peripheral nerves $[1,2]$. There is an increased prevalence of MSDs among the nurses of critical care units which significantly affects their health [3]. According to Bernal et al. [4], long-term exposure to a specific task at the workplace causes pain in muscles, bones, tendons, blood vessels, and nerves which eventually leads to MSDs.

Nursing is considered as one of the most exhausting jobs that are associated with an increased incidence of workrelated musculoskeletal disorders (MSDs) [5]. Nurses are reported to experience an increased prevalence of MSDs as compared to other system disorders [6]. According to the recent statistics [7], there is an increase in the prevalence of MSDs across developing as well as developed countries. As compared to other clinical settings, the nurses working in critical care units exert much physical effort to fulfill patient needs, which increases their susceptibility to MSDs [8,9]. A recent study conducted by Amer [5] reported that nurses working in Intensive Care Unit are at increased risk of developing lower back pain (79.3\%), knee pain (72.4\%), shoulder pain $(72.4 \%)$, neck pain $(62.1 \%)$, and elbow pain (8.6\%).

One of the major risk factors leading to the development of musculoskeletal disorders is work activities. Work activities that cause extreme fatigue in the lower and upper extremities, lower back, and neck lead to MSDs and such diseases are termed as occupational diseases [10]. One of the previous studies by Purani et al. [11] reported that MSDs 
develop because of the constant repetition of improper postures and movements during work. Another recent study by Epstein et al. [12] has affirmed that the risk of developing MSDs increases due to force of movement, monotonous tasks, lack of control over job, and poor communication skills. Besides, work conditions like pace of work, weight of handling object, and layout of working station also significantly influence the development of MSDs [13]. The development of musculoskeletal pain was discussed by Lietz et al. [14] and the analysis showed that the risk of MSDs increases on account of the use of vibrating equipment, adoption of consistent static posture, and utilization of psychomotor skills. Therefore, it can be affirmed that physical factors along with the occupational setting are correlated in the development of MSDs.

The occurrence of MSDs is generally higher among critical care nurses than that of nonspecialized nurses. This is specifically accurate for scrub nurses who are more prone to MSDs as being actively engaged to create and maintain the surgical field and passing medical equipment to surgeons [15]. Idiosyncrasies of their work tasks includes unusual motions, implementation of awkward and static postures, and continuous repetitive movements for protracted time periods, and lifting and holding up immense surgical instruments when aiding the surgeon and caring for the patient. [16]. In particular, critical care nurses have an even higher risk to develop MSDs if working full-time as critical nurses.

A lot of efforts and skills are required from the nurses of critical care units for catering their patient's need and, therefore, the risk of development of MSDs in them increases accordingly. It is a well-known fact that if a body position is maintained for a long time, it can lead to discomfort and fatigue [17]. Similarly, nurses of the critical care units hold their neck and shoulders in a fixed position and this consistent posture leads to the development of MSDs characterized by injuries and pain. For the last two decades, the development of MSDs has been reported more frequently in the nurses of critical care units as compared to the nurses of clinical care units. The development of MSDs in the nurses of the critical care units is a major setback for them as not only their treatment options are expensive but also do they reduce the quality of patient care. There is a need to increase awareness in the nurses of critical care units regarding the usage of proper procedures of handling and movements of patients/objects via developing coping strategies, educational programs, and implementation of special policies and procedures.

Previous studies have shown that the adoption of effective coping strategies and educational programs minimizes the incidence of work-related MSDs in the nurses and also increases their efficiency in giving quality care to the patients $[18,19]$. These studies have successfully identified several work-related MSDs and their treatment costs. However, none of the previous studies provided relevant information for the policymakers and planners to plan adequate policies and procedures to reduce staff absenteeism and in turn increase the quality of work with positive outcomes.
The role of occupational therapy entails adaptation and changes in work tasks, prevention of injury via education of employees and management, and ergonomic assessments. A critical care nurse would undertake the vocational element of the nurse with MSDs and assess the factors contributing to the injury throughout the work environment [20]. Research by Abu Tariah et al. [21] offers evidence for the effectiveness of interventions for preventing MSDs. An ergonomic assessment by the OT comprises the following movements to investigate the physical stress that it causes and mitigate adverse postures or repetitive muscle use. Changes to the task are suggested for enhancing body mechanics. The occupational therapists would further contribute to modifying the engineering controls of any transportation necessities of work tasks [22].

Therefore, the present study aims to determine work activities that lead to the development of MSDs in the nurses of critical care units and to provide relevant information required to devise preventive measures to manage those activities properly in the workplace. The study results would help in developing better programs and procedures for preparing nurses of critical care units by providing them with adequate knowledge about how to minimize the risk factors of MSDs. The research questions addressed by the study are as follows:

(i) What are the major risk factors that lead to the development of MSDs in nurses of critical care units?

(ii) Is there a significant association between demographic characteristics and occurrence of MSDs in nurses of critical care units?

\section{Subjects and Methods}

2.1. Setting. This study employed a cross-sectional study design to assess the work activities related to MSDs in nurses of critical care unit working at King Fahad University Hospital located in the city of Al-Khobar in the eastern province of Saudi Arabia. The study was conducted in the critical care unit of King Fahad Hospital for three months between February and April 2019.

2.2. Ethical Approval. This study approval was obtained from the Institute Review Board (IRB) of Imam Abdulrahman Bin Faisal University and the permission of the director of research of King Fahad Hospital was also acquired. Additionally, informed consent was duly obtained from each participant before recruiting them for the study.

2.3. Participants. A convenience sample of all nurses working in the surgical adult intensive care unit, medical adult intensive care unit, cardiac care unit, and emergency department were surveyed with a confidence level of $93 \%$ and a margin error of $7 \%$. The final sample included 100 nurses from critical care units who were exposed to the risk of developing MSDs because of consistent use of high and complex technologies. Following were the inclusion criteria 
for the study sample: the registered nurses who were working full-time in the emergency department and intensive care unit and directly involved in patient care. The exclusion criteria included part-time nurses, pregnant nurses, and those with recently diagnosed MSDs. In the first place, the voluntariness was ensured by asking participants to voluntarily participate in the study and the nurses who were not willing to participate in the study voluntarily were excluded. A total of 223 nurses were approached for data collection; however, only 100 questionnaires were received with complete details, with a response rate of $44.8 \%$ (Figure 1).

2.4. Data Collection. A structured close-ended questionnaire was used as a data collection instrument that comprised two parts:

(i) Part 1 gathered information related to gender, age, education level, height/weight, place of work, experience level, health problems, and awareness level through educational programs.

(ii) Part 2 included a self-administered questionnaire containing 29 items that investigated the effect of work activities on the development of MSDs.

This prevalidated questionnaire was adapted from Bin Homaid et al. [23]. Approval was obtained from the author through e-mail before adopting the questionnaire. The tool used for data collection consisted of 29 items (closed-ended structured questions) that were grouped into the following two domains:

(i) Risk factor of MSD (15 questions): it contained questions related to stress level at work (1 question), smoking (1 question), period of long standing and setting (2 questions), and weight and type of lifting objects and number of caring (object or patient) (3 questions), body mechanism for lifting or performing procedure (3 questions), and transfer and moving patient (5 questions).

(ii) MSD assessment in the nurses of critical care units (14 questions): it consisted of questions related to the location of aching area (1 question), nature of pain (5 questions), severity of pain (1 question), medical advice and treatment (4 questions), and effect and management of MSD-associated pain (3 questions).

The severity of pain was measured according to the Likert scale from 0 to 5: ranging from no pain to severe pain.

2.5. Data Analysis. The data collected through the questionnaire were entered, coded, and analyzed with the help of the IBM SPSS Statistic Program version 25.0. Descriptive statistics in the form of frequencies/percentages were used to present the categorical data, whereas mean/standard deviations were used to present the continuous data. Spearman's rank correlation coefficient was used to measure the association between sociodemographic factors and work-related activities to musculoskeletal dysfunction. $p$-value of less than 0.05 was considered statistically significant.

\begin{tabular}{|l|c|c|}
\hline What margin of error can you accept? & 7 & $\%$ \\
\hline $5 \%$ is a common choice & & \\
\hline & & \\
\hline What confidence level do you need? & 93 & $\%$ \\
\hline Typical choices are 90\%, 95\%, or 99\% & & \\
\hline & & \\
\hline What is the population size? & 223 & \\
\hline If you don't know, use 20000 & & \\
\hline & & \\
\hline What is the response distribution? & 50 & $\%$ \\
\hline Leave this as 50\% & & \\
\hline \hline Your recommended sample size is? & 96 & \\
\hline
\end{tabular}

Figure 1: Sampling criteria.

\section{Results}

The sociodemographic characteristics of nurses, including gender, age, BMI, education level, work experience in critical care unit, prolonged standing shift, and prolonged sitting shift, are presented in Table 1. The distribution of work activities leading to MSDs in the nurses of the critical care unit and the prevalence of musculoskeletal disorders as responded by the nurses are demonstrated in Table 2 .

Table 3 shows a statistically significant association of ankle/feet pain with normal weight (58\%), overweight (37\%), and obesity $(2 \%)(p$-value $=0.02)$. However, none of the other MSDs showed a statistically significant association with BMI. The association of 2-year work experience at critical care unit with MSDs in the nurses is presented in Table 4.

The association of sociodemographic characteristics with MSDs in the nurses of the critical care unit is presented in Table 5. The results show a significant association of age with lower back pain $(p$ value $=0.03)$ and neck pain $p$ value $=0.03) ;$ education level with thigh/hip pain ( $p$ value $=0.03)$; standing time with shoulder pain ( $p$ value $=0.04)$, knee pain ( $p$ value $=0.05)$, thigh/hip pain $(p$ value $=0.04)$, and hand $/$ wrist pain $(p$ value $=0.04)$.

Table 6 shows the association between the work activities and MSDs related to upper and lower body. The results clearly depict that there is a statistically significant and positive correlation in bending to lift item from floor with neck pain $(p=0.04)$ and upper back pain $(p=0.03)$, lower back pain $(p=0.004)$, hip/thigh pain $(p=0.05)$, and knee pain (0.04).

\section{Discussion}

The results of the current study have supported the universal hypothesis which states that work activities extensively expose the nurses of critical care units to MSDs. Similar results were deduced by Amer [5] and the results showed a significant relationship between work activities and MSDs in the nurses of critical care units. The increased prevalence of MSDs in the nurses is related to various risk factors that include long working shifts, working in awkward positions, stressful physical working conditions, and manual handling 
TABLE 1: Demographic profile of the nurses.

\begin{tabular}{|c|c|c|}
\hline Item & Measure & $\mathrm{N}(\%)$ \\
\hline \multirow[b]{2}{*}{ Gender } & Male & $23(23 \%)$ \\
\hline & Female & $77(77 \%)$ \\
\hline \multirow{5}{*}{ Age } & $25-30$ years & $49(49 \%)$ \\
\hline & $31-35$ years & $39(39 \%)$ \\
\hline & $36-40$ years & $5(5 \%)$ \\
\hline & $41-55$ years & $3(3 \%)$ \\
\hline & $>56$ years & $1(1 \%)$ \\
\hline \multirow{4}{*}{ BMI } & $<18.5$ (underweight) & $2(2 \%)$ \\
\hline & $18.5-24.9$ (normal) & $58(58 \%)$ \\
\hline & 25-29.9 (overweight) & $38(38 \%)$ \\
\hline & $>30$ (obese) & $2(2 \%)$ \\
\hline \multirow{3}{*}{ Education level } & Nursing diploma & $10(10 \%)$ \\
\hline & Nursing bachelor & $86(86 \%)$ \\
\hline & Postgraduate & $4(4 \%)$ \\
\hline \multirow{3}{*}{ Work experience } & $1-5$ years & $32(32 \%)$ \\
\hline & $6-10$ years & $48(48 \%)$ \\
\hline & $>10$ years & $20(20 \%)$ \\
\hline \multirow{3}{*}{ Critical care area experience } & $<1$ year & $16(16 \%)$ \\
\hline & $1-2$ years & $40(40 \%)$ \\
\hline & $>2$ years & $44(44 \%)$ \\
\hline \multirow{3}{*}{ Prolonged standing time during shift } & $1-4$ hours & $20(20 \%)$ \\
\hline & $5-8$ hours & $60(60 \%)$ \\
\hline & $>8$ hours & $20(20 \%)$ \\
\hline \multirow{3}{*}{ Prolonged sitting time during shift } & $1-4$ hours & $88(88 \%)$ \\
\hline & 5-8 hours & $7(7 \%)$ \\
\hline & $>8$ hours & $5(5 \%)$ \\
\hline
\end{tabular}

TABLE 2: Work activities leading to MSDs and prevalence of musculoskeletal disorders.

\begin{tabular}{ll}
\hline Item & $\mathrm{N}(\%)$ \\
\hline Work activities leading to MSDs & $(n=92) 92 \%$ \\
Patient lifting (bed ridden) & $(n=91) 91 \%$ \\
Repositioning patient in bed & $(n=90) 90 \%$ \\
Pulling patient up the bed & $(n=83) 83 \%$ \\
Transfer patient onto a stretcher & $(n=82) 82 \%$ \\
Ambulating a patient & $(n=78) 78 \%$ \\
Bending to lift item from floor & $(n=77) 77 \%$ \\
Transfer patient to bed/chair & $(n=56) 65 \%$ \\
Lifting objects above the waist & $(n=57) 57 \%$ \\
Rotating torso while bearing weight & \\
\hline Prevalence of musculoskeletal disorders & $(n=92) 92 \%$ \\
Lower back pain & $(n=56) 56 \%$ \\
Upper back pain & $(n=36) 36 \%$ \\
Shoulder pain & $(n=31) 31 \%$ \\
Neck pain & $(n=25) 25 \%$ \\
Ankle/feet pain & $(n=21) 21 \%$ \\
Wrist/hand pain & $(n=20) 20 \%$ \\
Knee pain & $(n=19) 19 \%$ \\
Hip/thigh pain & $(n=14) 14 \%$ \\
Elbow pain & \\
\hline
\end{tabular}

of patients. The prevalence of MSDs also increases with progressing age as $49 \%$ of the affected nurses were aged between 25 and 30 years and 39\% were aged between 31 and 35 years. The present study also shows a statistically significant relation of developing MSDs with lower back pain and neck pain $(p$ value $=0.03)$. These findings are supported by Tinubu et al. [2].

Many similar studies stated that nurses aged between 31 and 40 years were highly prone to develop MSDs. Attar [24] found that MSDs were highly prevalent in nurses aged more 
TABLE 3: Association of BMI related to MSDs.

\begin{tabular}{|c|c|c|c|c|c|}
\hline MSDs $n(100 \%)$ & Underweight 3 (3\%) & Normal weight $58(58 \%)$ & Overweight 37 (37\%) & Obese $2(2 \%)$ & $p^{*}$-value \\
\hline Neck pain & 3.2 & 61 & 32 & $3.2 \%$ & 0.35 \\
\hline Shoulder pain & 2 & 47.2 & 47.2 & 2.8 & 0.46 \\
\hline Elbow pain & 0 & 64.3 & 35.7 & $0 \%$ & 0.58 \\
\hline Wrist/hand pain & 0 & 11 & 10 & $0 \%$ & 0.76 \\
\hline Upper back pain & 1.8 & 60.7 & 33.9 & $3.6 \%$ & 0.35 \\
\hline Lower back pain & 2.2 & 56.5 & 38 & $3.3 \%$ & 0.37 \\
\hline Hip/thigh pain & 0 & 57.9 & 42.1 & $0 \%$ & 0.88 \\
\hline Knee pain & 0 & 45 & 55 & $0 \%$ & 0.36 \\
\hline Ankle/feet pain & 0 & 36 & 60 & $4 \%$ & $0.02^{*}$ \\
\hline
\end{tabular}

${ }^{*}$ Chi-square.

TABle 4: Association of 2-year work experience at critical care unit with MSDs.

\begin{tabular}{|c|c|c|c|}
\hline$p^{*}$-value & Correlation coefficient & MSDs $(100 \%)(n=100)$ & Critical care area experience year \\
\hline 0.910 & 0.011 & Neck pain & \\
\hline $0.001^{*}$ & -0.318 & Shoulder pain & \\
\hline 0.070 & -0.182 & Elbow pain & \\
\hline 0.370 & -0.091 & Wrist/hand pain & \\
\hline 0.753 & 0.032 & Upper back pain & $>2$ years \\
\hline 0.848 & -0.019 & Lower back pain & \\
\hline $0.010^{*}$ & -0.255 & Hip/thigh pain & \\
\hline $0.000^{*}$ & -0.343 & Knee pain & \\
\hline 0.116 & -0.158 & Ankle/feet pain & \\
\hline
\end{tabular}

${ }^{*}$ Spearman test.

TABLe 5: Association of sociodemographic related to MSDs among critical care nurses.

\begin{tabular}{|c|c|c|c|}
\hline$p^{*}$-value & Correlation coefficient & MSDs & Sociodemographic \\
\hline $0.03^{*}$ & 0.63 & \multirow{4}{*}{ Neck pain } & Age \\
\hline 0.91 & 0.12 & & Education level \\
\hline 0.73 & 0.03 & & Standing time \\
\hline 0.67 & 0.04 & & Sitting time \\
\hline 0.14 & -0.15 & \multirow{4}{*}{ Shoulder pain } & Age \\
\hline 0.92 & -0.01 & & Education level \\
\hline $0.04^{*}$ & 0.66 & & Standing time \\
\hline 0.43 & 0.07 & & Sitting time \\
\hline 0.67 & -0.04 & \multirow{4}{*}{ Elbow pain } & Age \\
\hline 0.40 & -0.10 & & Education level \\
\hline 0.07 & -0.18 & & Standing time \\
\hline 0.21 & -0.12 & & Sitting time \\
\hline 0.39 & -0.08 & \multirow{4}{*}{ Wrist/hand pain } & Age \\
\hline 0.47 & -0.08 & & Education level \\
\hline $0.05^{*}$ & -0.75 & & Standing time \\
\hline 0.67 & -0.04 & & Sitting time \\
\hline 0.17 & 0.13 & \multirow{4}{*}{ Upper back pain } & Age \\
\hline 0.61 & -0.07 & & Education level \\
\hline 0.75 & -0.03 & & Standing time \\
\hline 0.08 & 0.17 & & Sitting time \\
\hline $0.03^{*}$ & 0.89 & \multirow{4}{*}{ Lower back pain } & Age \\
\hline 0.94 & -0.05 & & Education level \\
\hline 0.56 & -0.05 & & Standing time \\
\hline 0.99 & -0.00 & & Sitting time \\
\hline 0.78 & -0.02 & \multirow{4}{*}{ Hip/thigh pain } & Age \\
\hline $0.03^{*}$ & -0.64 & & Education level \\
\hline $0.004^{*}$ & -0.78 & & Standing time \\
\hline 0.53 & 0.06 & & Sitting time \\
\hline
\end{tabular}


TABle 5: Continued.

\begin{tabular}{|c|c|c|c|}
\hline$p^{*}$-value & Correlation coefficient & MSDs & Sociodemographic \\
\hline 0.08 & -0.17 & \multirow{4}{*}{ Knee pain } & Age \\
\hline 0.41 & -0.08 & & Education level \\
\hline $0.005^{*}$ & -0.77 & & Standing time \\
\hline 0.53 & -0.06 & & Sitting time \\
\hline 0.26 & -0.11 & \multirow{4}{*}{ Ankle/feet pain } & Age \\
\hline 0.34 & -0.09 & & Education level \\
\hline 0.14 & -0.14 & & Standing time \\
\hline 0.49 & 0.07 & & Sitting time \\
\hline
\end{tabular}

${ }^{*}$ Spearman test.

TABLE 6: Association of work activities related to upper and lower body MSDs among studied critical care nurses.

\begin{tabular}{|c|c|c|c|}
\hline$p^{*}$-value & Correlation coefficient & MSDs & Work activities \\
\hline Upper bo & & \multirow{10}{*}{ Neck pain } & \\
\hline 0.15 & 0.14 & & Heaviest object lifted \\
\hline 0.20 & 0.12 & & Lifting objects above the waist \\
\hline 0.88 & 0.01 & & Rotating torso while bearing weight \\
\hline $0.04^{*}$ & 0.99 & & Bending to lift item from floor \\
\hline 0.56 & 0.05 & & Transfer patient to bed/chair \\
\hline 0.06 & 0.18 & & Transfer patient onto a stretcher \\
\hline 0.37 & 0.08 & & Ambulating a patient \\
\hline 0.13 & 0.15 & & Pulling patient up the bed \\
\hline 0.18 & 0.13 & & Repositioning patient in bed \\
\hline 0.13 & 0.15 & \multirow{9}{*}{ Shoulder pain } & Heaviest object lifted \\
\hline 0.79 & 0.02 & & Lifting objects above the waist \\
\hline 0.29 & -0.10 & & Rotating torso while bearing weight \\
\hline 0.14 & 0.14 & & Bending to lift item from floor \\
\hline 0.26 & 0.11 & & Transfer patient to bed/chair \\
\hline 0.94 & 0.00 & & Transfer patient onto a stretcher \\
\hline 0.79 & 0.02 & & Ambulating a patient \\
\hline 0.27 & 0.11 & & Pulling patient up the bed \\
\hline 0.10 & 0.13 & & Repositioning patient in bed \\
\hline 0.42 & -0.081 & \multirow{9}{*}{ Elbow pain } & Heaviest object lifted \\
\hline 0.51 & -0.09 & & Lifting objects above the waist \\
\hline 0.08 & -0.17 & & Rotating torso while bearing weight \\
\hline 0.95 & -0.00 & & Bending to lift item from floor \\
\hline 0.88 & 0.01 & & Transfer patient to bed/chair \\
\hline 0.21 & -0.12 & & Transfer patient onto a stretcher \\
\hline 0.25 & 0.11 & & Ambulating a patient \\
\hline 0.56 & -0.05 & & Pulling patient up the bed \\
\hline 0.20 & 0.12 & & Repositioning patient in bed \\
\hline 0.84 & -0.020 & \multirow{9}{*}{ Wrist/hand pain } & Heaviest object lifted \\
\hline 0.74 & -0.03 & & Lifting objects above the waist \\
\hline 0.33 & -0.09 & & Rotating torso while bearing weight \\
\hline 0.12 & 0.15 & & Bending to lift item from floor \\
\hline 0.29 & 0.10 & & Transfer patient to bed/chair \\
\hline 0.35 & -0.09 & & Transfer patient onto a stretcher \\
\hline 0.89 & -0.01 & & \\
\hline 0.93 & 0.00 & & Ambulating a patient pulling patient up the bed \\
\hline 0.45 & 0.07 & & Repositioning patient in bed \\
\hline
\end{tabular}


TABLE 6: Continued.

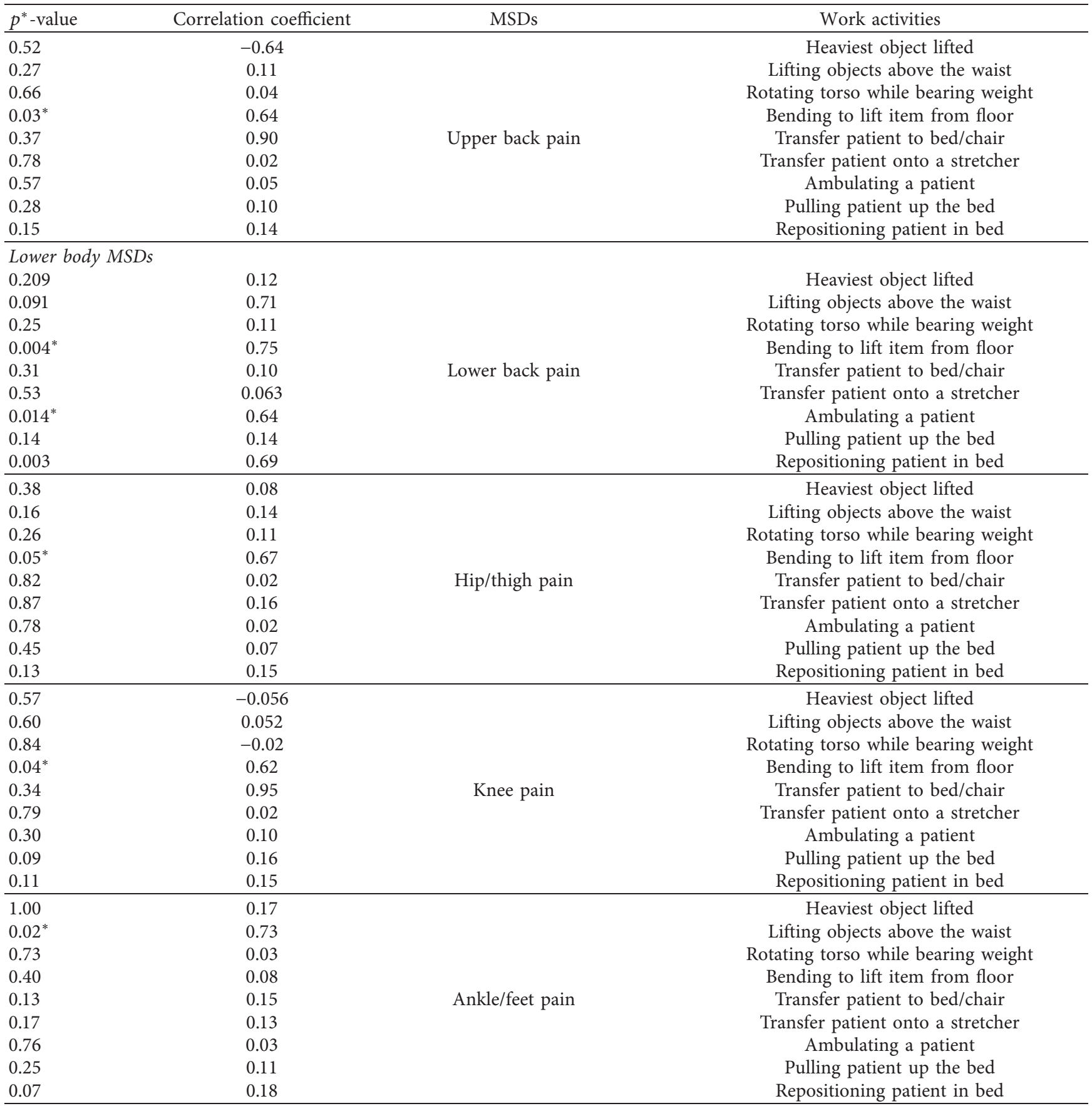

${ }^{*}$ Spearman test.

than 30 years unlike the nurses aged less than 30 years. This variation may also be due to the difference in tasks and procedures assigned to nurses in different clinical settings. The nurses of critical care units with experience of 2 years were likely to develop knee pain $(p$ value $=0.000)$, shoulder pain $(p$ value $=0.000)$, and thigh/hip pain $(p$ value $=0.01)$. The present findings show that most of the nurses (44\%) experienced initial symptoms of MSDs in the first two years of their clinical practice and this result was in line with the results of Tinubu et al. [2].
There is a significant positive association of BMI with the development of MSDs in the form of feet and ankle pain $(p$ value $=0.02)$. These findings are in agreement with the study conducted by Aljerian et al. [25] reporting lower back pain, knee pain, and upper back pain among 63.3\%, 41.4\%, and $40 \%$ of the nurses of critical care units. On the contrary, Bin Homaid et al. [24] identified no significant association between MSDs and demographic characteristics of nurses including their age, BMI, and working conditions. A recent study conducted by Yan et al. [26] also found no association 
between work experience (6-15 years) and development of MSDs in the nursing staff. This inconsistency might be attributed to the age of the nurses considered in both studies.

According to the current study, a long-standing time of 5 to 8 hours is statistically significant for developing MSDs in the form of knee pain ( $p$ value $=0.005)$, hand/wrist pain $(p$ value $=0.004)$, and thigh/hip pain $(p$ value $=0.005)$ among the nurses of critical care units. In a similar context, Bernal et al. [4] identified that prolonged standing increased the risk of spinal loading and shrinkage. It has also been observed that, as compared to the more educated nurses, less educated nurses were at greater risk of experiencing symptoms of MSDs [27]. This might be because more educated nurses are well aware of the policies and procedures of their tasks.

Concerning the MSDs, the current study reported that most of the nurses (92\%) suffered from lower back pain, which was followed by upper back pain (56\%), shoulder pain (36\%); neck pain $(31 \%)$, ankle pain $(25 \%)$, hand/wrist pain $(21 \%)$, knee pain $(20 \%)$, thigh/hip pain $(19 \%)$, and elbow pain $(14 \%)$. The high rate of lower back pain was also reported by Amer [5] as his study showed that most of the nurses $(79.3 \%)$ suffered from lower back pain. These results are further corroborated by the study of Aljerian et al. [28] which showed that more than three-quarters of the nurses suffered from lower back pain followed by neck pain. On the contrary, few studies narrated that the lower back was the least affected body part in the nurses [27, 29]. This variance may be attributed to various procedures, activities, or tasks performed by the nurses.

In addition, critical care nurses must retain in critical situations at all times, affecting awkward and prolonged static postures, upper extremity strain, and constant trunk flexion. Therefore, a prolonged static position is ideally recognized to be more disadvantageous as compared to a dynamic posture because of higher levels of lactic toxins and acidosis caused by the former.

Some of the previous studies reported that neck bending and pushing/pulling heavy objects were the most perceived job risk factors [28]. Similarly, the current study also highlights carrying, lifting, or moving heavy material or equipment as the major risk factors leading to MSDs. The differences found in the prevalence of work-related risk factors are attributed to the differences in the working conditions and tasks performed by the nurses in different units, hospitals, and countries. In fact, surgical instruments are rarely designed based on standard ergonomic principles that would ease their handling by health care providers. The ergonomic circumstances can be an essential factor in addition to the ergonomic design of surgical instruments. Surgical instrument makers must undertake encompassing professional employees into the design of surgical instruments for encompassing user's experience. In addition, healthcare professionals must be involved in the design and remodeling of the operating room for creating a user-centered work environment. Additionally, adversely designed instruments can indeed elevate hand, finger, and wrist strains of operators, which make these subjects more prone to developing upper limb disabilities. Therefore, a more operator-friendly design would definitely assist in reducing the physical strain for critical care nurses as well as surgeons in the operating room.

It is quite clear that an appropriate assessment of the physical strain endured by critical care nurses would benefit the integration of occupational health measures intended to reduce the risk of MSDs. Therefore, it is important for introducing innovative technical measurements able to assess objectively the physical workload for determining particular ergonomic risk factors. A task analysis is assumed a more viable approach for conducting this type of evaluation since motion sensors and electrodes could interfere with activities of operators. In addition, a task analysis would facilitate in order to assess type-specific surgical procedures on the basis of a holistic approach undertaking all most appropriate components of human skills.

Even though the current study is helpful for the development of specific programs and policies for the nurses of critical care nurses, there are also some limitations. The small sample size considered in this study could not be used for obtaining generalized findings across different regions in Saudi Arabia. Moreover, some of the collected data including information about prevention method and specific treatment were subjective; therefore, it may provide exaggeration or be presented as a limiting factor. Another limitation of our study is that albeit the response rate was good, a nonresponse analysis could not be performed due to the lack of nonrespondent data. Consequently, a bias due to selective nonresponse cannot be ruled out. For these reasons, our results should be interpreted with caution. Finally, the study results are not completely justified with literature support as there are only a few studies that have focused on the assessment of the quality of nurses with respect to MSDs.

\section{Conclusion}

The results of this study demonstrate a significant association between sociodemographic characteristics (age, BMI, and work experience) and development of MSDs in nurses of critical care units. The work activities having a significant association with the development of MSDs include repositioning of patients in bed, bending to lift items from floor, and lifting object above waist. Moreover, clinical characteristics such as prolonged standing time and increased stress level have been found to be significantly associated with MSDs. The results show that the majority of the nurses suffered from lower back pain (92\%) and upper back pain (56\%). There was a significant negative impact of the stated work activities on the quality of patient care provided by the nurses of critical care units. Based on the results deduced in this study, it is recommended that critical care unit nurses need to be educated about the risk factors that may lead to the development of MSDs and effective strategies should be formulated for utilizing proper procedures to move, handle, and position the patients of critical care unit. Concerning the clinical practice, the study suggests that the critical care unit should be equipped with an adequate number of nurses to minimize work pressure on each nurse in order to avoid the development of MSDs. Moreover, an adequate number of 
nurses should be hired in critical care setting of nurses to avoid MSD development. However, future studies need to focus on the variables that initiate MSDs including stress, resilience, work environment, fatigue, and sleep privation. Examination of the work activities that lead to MSDs in nurses of different regions should be thoroughly conducted to promote the generalization of study findings.

\section{Data Availability}

The datasets used and analyzed during the current study are available from the corresponding author upon reasonable request.

\section{Conflicts of Interest}

The authors declare no conflicts of interest.

\section{Acknowledgments}

The authors are thankful to all the associated personnel in any reference who contributed to the purpose of this research.

\section{References}

[1] R. F. Zernicke and W. C. Whiting, "Mechanisms of musculoskeletal injury," Biomechanics in Sport, pp. 507-522.

[2] B. M. Tinubu, C. E. Mbada, A. L. Oyeyemi, and A. A. Fabunmi, "Work-related musculoskeletal disorders among nurses in ibadan, south-west Nigeria: a cross-sectional survey," BMC Musculoskeletal Disorders, vol. 11, no. 1, 2010.

[3] S. Mehralizadeh, A. Dehdashti, and M. Motalebi Kashani, "Structural equation model of interactions between risk factors and work-related musculoskeletal complaints among Iranian hospital nurses," Work, vol. 57, no. 1, pp. 137-146, 2017.

[4] D. Bernal, J. Campos-Serna, A. Tobias, S. Vargas-Prada, F. G. Benavides, and C. Serra, "Work-related psychosocial risk factors and musculoskeletal disorders in hospital nurses and nursing aides: a systematic review and meta-analysis," International Journal of Nursing Studies, vol. 52, no. 2, pp. 635-648, 2015.

[5] S. Amer, "Work-Related musculoskeletal symptoms among nurse staff in ismailia, Egypt," Egyptian Journal of Occupational Medicine, vol. 42, no. 1, pp. 61-78, 2018.

[6] M. Attarchi, S. Raeisi, M. Namvar, and M Golabadi, "Association between shift working and musculoskeletal symptoms among nursing personnel," Iranian Journal of Nursing and Midwifery Research, vol. 19, pp. 309-14, 2014.

[7] H. D. Luan, N. T. Hai, P. T. Xanh et al., "Musculoskeletal disorders: prevalence and associated factors among district hospital nurses in haiphong, vietnam," BioMed Research International, vol. 2018, Article ID 3162564, 9 pages, 2018.

[8] D. Sezgin and M. N. Esin, "Predisposing factors for musculoskeletal symptoms in intensive care unit nurses," International Nursing Review, vol. 62, no. 1, pp. 92-101, 2015.

[9] A. Amila, E. Sembiring, and R. Siregar, "Low back pain in icu and emergency unit nurses at sari mutiara general hospital medan," Indonesian Nursing Journal of Education and Clinic (Injec), vol. 2, no. 2, pp. 246-252, 2018.

[10] M. D. Hossain, A. Aftab, M. H. Al Imam et al., "Prevalence of work related musculoskeletal disorders (WMSDs) and ergonomic risk assessment among readymade garment workers of Bangladesh: a cross sectional study," PLoS one, vol. 13, no. 7, Article ID e0200122, 2018.

[11] R. Purani, N. Vyas, and M. Sheth, "Prevalence of low back pain in salespersons and its association with ergonomic risk factors in Ahmedabad, Gujarat: a cross-sectional survey," Medical Journal of Dr. D.Y. Patil University, vol. 9, no. 3, pp. 331-335, 2016.

[12] S. Epstein, E. H. Sparer, B. N. Tran et al., "Prevalence of workrelated musculoskeletal disorders among surgeons and interventionalists," JAMA Surgery, vol. 153, no. 2, Article ID e174947, 2018.

[13] J.-C. Liao, C.-H. Ho, H.-Y. Chiu et al., "Physiotherapists working in clinics have increased risk for new-onset spine disorders," Medicine, vol. 95, no. 32, Article ID e4405, 2016.

[14] J. Lietz, A. Kozak, and A. Nienhaus, "Prevalence and occupational risk factors of musculoskeletal diseases and pain among dental professionals in Western countries: a systematic literature review and meta-analysis," PLoS one, vol. 13, no. 12, Article ID e0208628, 2018.

[15] M. Clari, G. Garzaro, M. Di Maso et al., "Upper limb workrelated musculoskeletal disorders in operating room nurses: a multicenter cross-sectional study," International Journal of Environmental Research and Public Health, vol. 16, no. 16, p. 2844, 2019.

[16] K. Getie, G. Kahsay, A. Kassaw, G. Gomera, A. Alamer, and T. Hailu, "Ankle and foot pain and associated factors among nurses at ayder comprehensive specialized hospital, mekelle, Ethiopia: cross-sectional study," Journal of Pain Research, vol. 14, pp. 83-92, 2021.

[17] I. Halim and A. Rahman Omar, "Development of prolonged standing strain index to quantify risk levels of standing jobs," International Journal of Occupational Safety and Ergonomics, vol. 18, no. 1, pp. 85-96, 2012.

[18] Y.-C. Chung, C.-T. Hung, S.-F. Li et al., "Risk of musculoskeletal disorder among Taiwanese nurses cohort: a nationwide population-based study," BMC Musculoskeletal Disorders, vol. 14, no. 1, 2013.

[19] P. Yarmohammadi, F. Samadzadeh, N. Kasiri et al., "A survey of the perspectives of the female nursing personnel regarding the prevention of low back pain and its appropriate medical treatments," International Archives of Health Sciences, vol. 4, no. 3, p. 68, 2017.

[20] P. Soylar and A. Ozer, "Evaluation of the prevalence of musculoskeletal disorders in nurses: a systematic review," Medical Sciences, vol. 7, pp. 479-485, 2018.

[21] H. Abu Tariah, S. Nafaic, M. Alajmia, F. Almutairi, and B. Alanazi, "Work-Related musculoskeletal disorders in nurses working in the Kingdom of Saudi Arabia," Work, no. Preprint, pp. 1-8, 2020.

[22] W. Thinkhamrop, K. Sawaengdee, V. Tangcharoensathien et al., "Burden of musculoskeletal disorders among registered nurses: evidence from the Thai nurse cohort study," BMC Nursing, vol. 16, no. 1, pp. 1-9, 2017.

[23] M. Bin Homaid, D. Abdelmoety, W. Alshareef et al., "Prevalence and risk factors of low back pain among operation room staff at a Tertiary Care Center, Makkah, Saudi Arabia: a cross-sectional study," Annals of Occupational and Environmental Medicine, vol. 28, no. 1, 2016.

[24] S. M. Attar, "Frequency and risk factors of musculoskeletal pain in nurses at a tertiary centre in Jeddah, Saudi Arabia: a cross sectional study," BMC Research Notes, vol. 7, no. 1, 2014.

[25] N. Aljerian, S. Alshehri, E. Masudi, A. M. Albawardi, F. Alzahrani, and R. Alanazi, "The prevalence of 
musculoskeletal disorders among EMS personnel in Saudi Arabia, riyadh," The Egyptian Journal of Hospital Medicine, vol. 73, no. 1, pp. 5777-5782, 2018.

[26] P. Yan, Y. Yang, and L. Zhang, "Correlation analysis between work-related musculoskeletal disorders and the nursing practice environment, quality of life, and social support in the nursing professionals," Medicine, vol. 97, no. 9, Article ID e0026, 2018.

[27] D. R. Smith, J. Choi, M. Ki, J. Kim, and Z. Yamagata, "Musculoskeletal disorders among staff in south korea's largest nursing home," Environmental Health and Preventive Medicine, vol. 8, no. 1, pp. 23-28, 2003.

[28] H. A. Zayed, S. M. Saied, M. Rania et al., "Work-Related Musculoskeletal Disorders among nursing staff of Tanta University Hospitals: pattern, risk factors, and coping strategies," EJCM, vol. 37, 2019.

[29] E. Enas, E. H. Samuel, E.-M. Raga, and E.-B. AS, "Prevalence and associated factors of musculoskeletal complaints among nurses of mansoura university children hospital," Egyptian Journal of Occupational Medicine, vol. 42, no. 2, pp. 151-166, 2018. 